\title{
Inhibitory effects of iron depletion plus eribulin on the breast cancer microenvironment
}

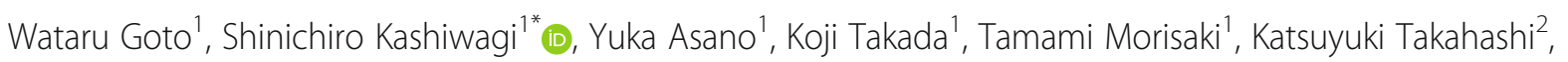
Hisakazu Fujita ${ }^{3}$, Masatsune Shibutani ${ }^{4}$, Ryosuke Amano ${ }^{5}$, Tsutomu Takashima', Shuhei Tomita², Kosei Hirakawa ${ }^{1,4}$ and Masaichi Ohira ${ }^{1,4}$

\begin{abstract}
Background: Iron is required for the proliferation of cancer cells, and its depletion suppresses tumor growth. Eribulin mesylate (eribulin), a non-taxane microtubule inhibitor, disrupts the tumor microenvironment via vascular remodeling and obstruction of the epithelial-mesenchymal transition (EMT). Herein, we investigated the effects of the iron chelator on tumor-related properties of breast cancer cells and the effects of iron chelator plus eribulin on tumor growth in vivo.
\end{abstract}

Methods: Two triple-negative breast cancer (TNBC) cell lines, MDA-MB-231 and BT-549, and one hormone-receptor positive breast cancer cell line, MCF-7, were used in our study. Cell proliferation, cell migration, cell cycle position, and gene expression were analyzed via MTT assays, wound-healing assays, flow cytometry, and quantitative realtime-polymerase chain reaction, respectively. For the in vivo experiments, mice with breast cancer xenografts were treated with the inhibitors, alone or together, and tumor volume was determined.

Results: Iron chelator inhibited breast cancer cell proliferation and decreased the proportion of S-phase cells. Conversely, it induced hypoxia, angiogenesis, EMT, and immune checkpoints, as determined by quantifying the expression of marker mRNAs in MDA-MB-231 and MCF-7 cells. Eribulin suppressed the expression of the hypoxia and EMT related marker mRNAs in the presence of iron chelator. Iron chelator plus eribulin inhibited tumor growth in vivo to a greater extent than did either inhibitor alone.

Conclusions: Although iron chelator induces oncogenic events (hypoxia, angiogenesis, EMT, and immune checkpoints), it may be an effective treatment for breast cancer when administered in combination with eribulin.

Keywords: Iron chelator, Eribulin mesylate, Breast cancer, Xenograft, Epithelial-mesenchymal transition, Immune checkpoints

\footnotetext{
* Correspondence: spqv9ke9@view.ocn.ne.jp

'Department of Breast and Endocrine Surgery, Osaka City University

Graduate School of Medicine, 1-4-3 Asahi-machi, Abeno-ku, Osaka 545-8585,

Japan

Full list of author information is available at the end of the article
}

(c) The Author(s). 2020 Open Access This article is licensed under a Creative Commons Attribution 4.0 International License, which permits use, sharing, adaptation, distribution and reproduction in any medium or format, as long as you give appropriate credit to the original author(s) and the source, provide a link to the Creative Commons licence, and indicate if changes were made. The images or other third party material in this article are included in the article's Creative Commons licence, unless indicated otherwise in a credit line to the material. If material is not included in the article's Creative Commons licence and your intended use is not permitted by statutory regulation or exceeds the permitted use, you will need to obtain permission directly from the copyright holder. To view a copy of this licence, visit http://creativecommons.org/licenses/by/4.0/ The Creative Commons Public Domain Dedication waiver (http://creativecommons.org/publicdomain/zero/1.0/) applies to the data made available in this article, unless otherwise stated in a credit line to the data. 


\section{Background}

Iron is an essential requirement for both normal and cancer cell viability and proliferation. The protein transferrin shuttles iron from the serum to the cell interior via transferrin receptor 1 (TfR1) [1]. Cancer cells have significantly higher levels of TfR1 than do normal cells and hence take up iron more rapidly [2]. Iron has been shown to increase the expression of cyclin D1, D2, and D3, which facilitates G1/S cell cycle progression [3], and is distributed in the hemoglobin of red blood cells, where it promotes oxygen transport. Conversely, iron depletion inhibits cyclin D1 expression [3, 4], suppresses tumor growth [5], and reduces serum hemoglobin levels and oxygen supply to tissues $[6,7]$. These observations implicate iron in tumor progression; however, the effect of iron on the epithelial-mesenchymal transition (EMT) or immune checkpoints has not been examined sufficiently.

Eribulin mesylate (eribulin), a non-taxane, synthetic inhibitor of microtubule dynamics, induces $\mathrm{G} 2 / \mathrm{M}$ cell cycle arrest and subsequent apoptosis [8-10]. Interestingly, it also has some unique anticancer effects in breast cancer cells, such as improvement of tumor perfusion, hypoxia [11], and the EMT [12]. We previously investigated these effects using clinical tumor samples [13] and suggested that eribulin enhanced the antitumor immune response by inactivating immune checkpoints [14]. The present study investigated the mechanism of iron control therapy in breast cancer in terms of the tumor microenvironment. We also determined whether the combination of iron depletion and eribulin was a potentially effective treatment for breast cancer.

\section{Methods}

\section{Cell lines and culture conditions}

Two triple-negative breast cancer (TNBC) cell lines, MDA-MB-231 and BT-549, and one hormone-receptor positive breast cancer (HRBC) cell lines, MCF-7, were from the American Type Culture Collection (Rockville, MD, USA). Cells were cultured in Dulbecco's Modified Eagle's Medium (DMEM; Wako, Osaka, Japan) supplemented with $10 \%$ fetal bovine serum (FBS; Equitech-Bio, Kerrville, TX, USA), $100 \mathrm{U} / \mathrm{mL}$ penicillin (Gibco, Grand Island, NE, USA), and $100 \mu \mathrm{g} / \mathrm{mL}$ streptomycin at $37^{\circ} \mathrm{C}$ in humidified air with $5 \% \mathrm{CO}_{2}$. The culture medium was replaced every 3 days.

\section{Compounds}

Deferoxamine (DFO), an iron-chelating agent, was purchased from Novartis (Basel, Switzerland). Deferasirox, an another iron-chelator, was purchased from Novartis Pharma (Basel, Switzerland). Eribulin was provided by Eisai Co. (Tokyo, Japan).

\section{Cytotoxicity assay}

The sensitivity of the three human breast cancer cell lines to two iron chelators was evaluated using a cell proliferation (MTT) assay kit according to the manufacturer's instructions (Sigma-Aldrich, St. Louis, MO, USA). Briefly, cells $\left(1 \times 10^{3}\right.$ cells/well in 96-well plates $)$ were cultured for $24 \mathrm{~h}$ in $90 \mu \mathrm{L}$ of DMEM with $10 \%$ FBS. A $10-\mu \mathrm{L}$ aliquot of medium containing the indicated concentration of DFO or deferasirox was then added to each well. $72 \mathrm{~h}$ after incubation, $10 \mu \mathrm{L}$ of the MTT reagent was added to each well; $2 \mathrm{~h}$ later, the medium was discarded and replaced by $100 \mu \mathrm{L}$ of dimethyl sulfoxide. After shaking the plates for $10 \mathrm{~min}$, the plate was measured as absorbance at $510 \mathrm{~nm}$ with a microplate reader (Perkin-Elmer, Waltham, MA, USA). Three independent experiments were performed [15].

\section{Wound-healing assay}

MDA-MB-231 cells were cultured in 96-well plates. After the cells reached $80-90 \%$ confluence, a wound was created in the cell monolayer using the WoundMaker tool (Essen Bioscience, Ann Arbor, MI, USA). The cells were cultured in DMEM with $1 \%$ FBS and 10 or $100 \mu \mathrm{M}$ DFO for $30 \mathrm{~h}$. Scratched fields were photographed every $2 \mathrm{~h}$ using an Incucyte Live-Cell Imaging System (Essen Bioscience). The degree of cell migration was calculated as $100 \times$ the wound closure area at each time point/the wound area at time 0 [16].

\section{Analysis of cell cycle progression}

Cells $\left(1 \times 10^{6}\right.$ cells/well) were plated into six-well tissue culture plates. After $24 \mathrm{~h}$, the cells were harvested and washed two times with phosphate-buffered saline and stained with the CycleTEST ${ }^{\text {max }}$ PLUS DNA Reagent kit according to the manufacturer's instructions (Becton Dickinson Biosciences, CA-San Jose, USA). Staining intensity was quantified using BD LSR II flow cytometer with FACSDiva ${ }^{\text {Th }}$ software (Becton Dickinson Biosciences) [17, 18].

Quantitative real-time-polymerase chain reaction (qRT-PCR) Total RNA was extracted from cells using the RNeasy Mini kit (Qiagen, Valencia, CA, USA). cDNA was synthesized using ReverTra Ace qPCR RT Master Mix (TOYOBO, Osaka, Japan). The RT step was performed at $37^{\circ} \mathrm{C}$ for 15 min, $50^{\circ} \mathrm{C}$ for $5 \mathrm{~min}$, and then $98^{\circ} \mathrm{C}$ for $5 \mathrm{~min}$. cDNA was amplified via qRT-PCR with Taq DNA polymerase (Nippon Gene, Tokyo, Japan) and the StepOnePlus RT-PCR system (Applied Biosystems, Foster City, CA, USA). The following TaqMan gene expression assays for used: assay ID, Hs00154208 (CA9); assay ID, Hs00911700 (KDR); assay ID, Hs00983056 (CDH2); assay ID, Hs00232783 (ZEB1); assay ID, Hs01125301 (CD274); and assay ID, Hs02758991 (GAPHD) (Applied Biosystems). RT-PCR was performed at

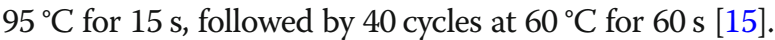




\section{In vivo tumor model}

In vivo experiments were conducted on 4-week-old female athymic BALB/c nu/nu mice obtained from CLEA Japan (Tokyo, Japan). The animal experimental protocol was approved by Ethical Committee of the Osaka City University, Osaka, Japan. All studies on mice were conducted in accordance with the National Institute of Health (NIH) 'Guide for the Care and Use of Laboratory

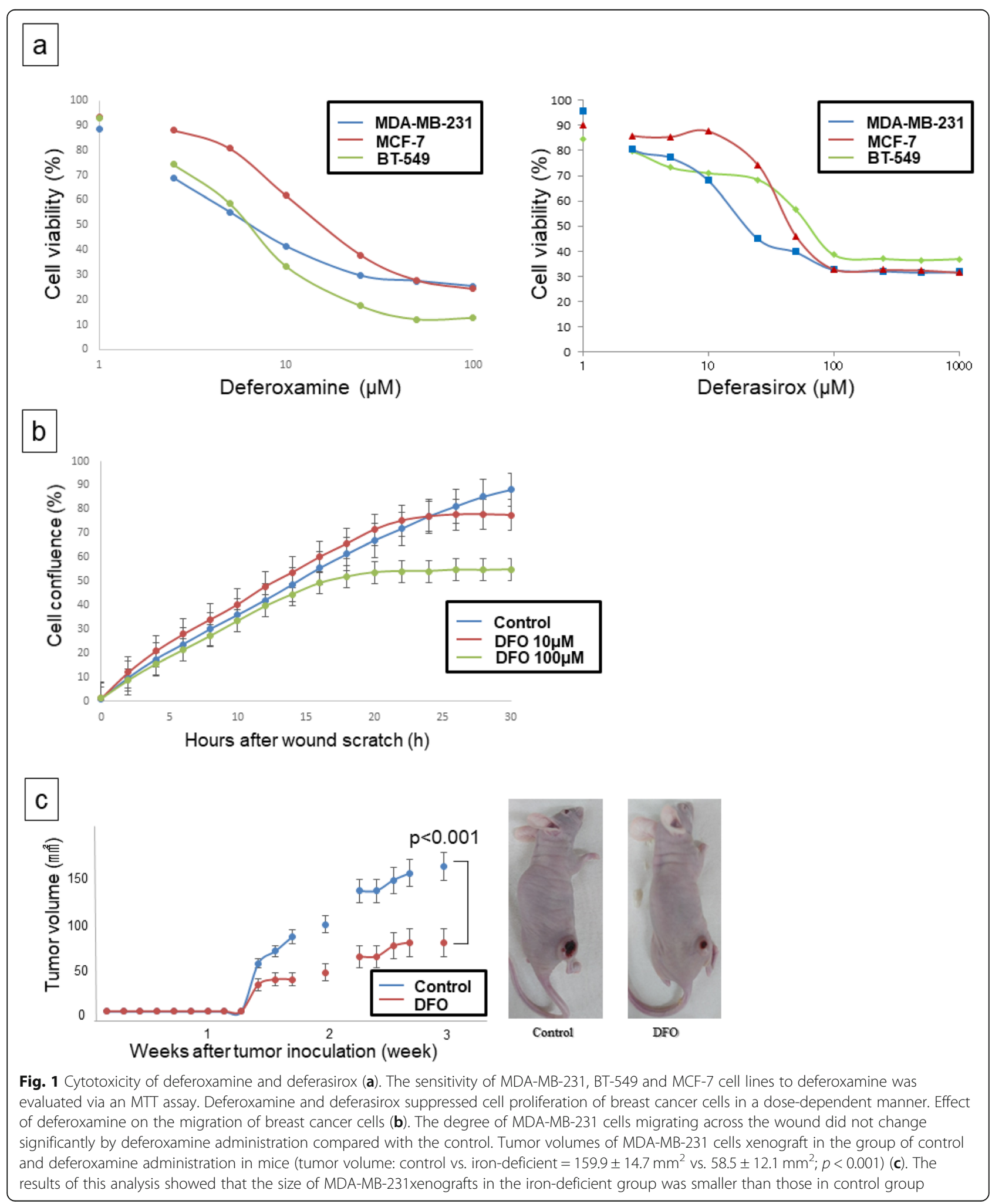


Animals'. The mice were housed in a standard animal laboratory with ad libitum access to food and water. MDAMB-231 cells $\left(10^{7}\right.$ cells $)$ were suspended in $100 \mu \mathrm{L}$ of DMEM, and injected into the backs of the mice. After a week, the mice were randomized into two groups: (1) control (saline alone) and (2) DFO (20 mg/kg/day, 5 days/ week). For evaluation of the combination therapy, the mice were randomized into four groups: (1) control (saline alone), (2) DFO alone, (3) eribulin alone $(0.8 \mathrm{mg} / \mathrm{kg} /$ day, 5 days/week), and (4) DFO plus eribulin.

Both DFO and eribulin were dissolved in DMEM without FBS. DFO was directly injected into the tumor, and eribulin was intravenously administered. The resultant tumor volumes (length $\times$ width) were measured weekly. Animals were euthanized via isoflurane (Mylan, PA, USA) ( $1 \mathrm{ml}$ per one mouse) and cervical dislocation, and autopsied at 6 weeks after cell inoculation [17]. In sacrifice, animals were unconscious.

\section{Statistical analysis}

Statistical analyses were performed with JMP13 software (SAS Institute, Cary, NC, USA). Student's t-test was used to compare data between groups. A $p$ value $<0.05$ was considered statistically significant.

\section{Results}

Effects of iron chelator on breast cancer cell proliferation and migration

DFO and deferasirox suppressed the proliferation of all breast cancer cell lines in a dose-dependent manner in
MTT assays (Fig. 1a). Wound healing assays showed that treatment with DFO inhibited the proliferation of MDAMB-231 breast cancer cells but not the migration (Fig. 1b). DFO also suppressed tumor growth in nude mice with subcutaneous MDA-MB-231 xenografts (tumor volume: control vs. iron-deficient $=159.9 \pm 14.7 \mathrm{~mm}^{2}$ vs. $58.5 \pm 12.1 \mathrm{~mm}^{2} ; p<0.001$ ) (Fig. 1c). No significant side effects were observed in DFO-treated mice. As shown via flow cytometry, DFO reduced the proportion of MDA-MB-231 cells in S phase (Fig. 2). This finding suggests that iron depletion inhibits the G1/S transition.

Effects of DFO on mRNA expression in breast cancer cells In these experiments, cells were treated with or without DFO or deferasirox for 3 days. Total RNA was extracted, and the expression levels of the indicated mRNAs were quantified via qRT-PCR.

The effects of iron depletion on hypoxia and angiogenesis were examined by measuring the mRNA levels of $C A 9$ and $K D R$, respectively. $C A 9$ encodes carbonic anhydrase 9 , which is overexpressed in hypoxic conditions, and $K D R$ encodes vascular endothelial growth factor receptor 2, which promotes angiogenesis. Notably, DFO upregulated CA9 expression in MDA-MB-231 and MCF-7 cells, indicating that iron deficiency induces hypoxia (Fig. 3a). It also slightly increased the mRNA levels of KDR in MDA-MB-231 and MCF-7 (Fig. 3b).

The effects of iron deficiency by DFO on the EMT and immune checkpoints were assessed by measuring the mRNA levels of $C D H 2$ and $C D 274$, respectively. $C D H 2$

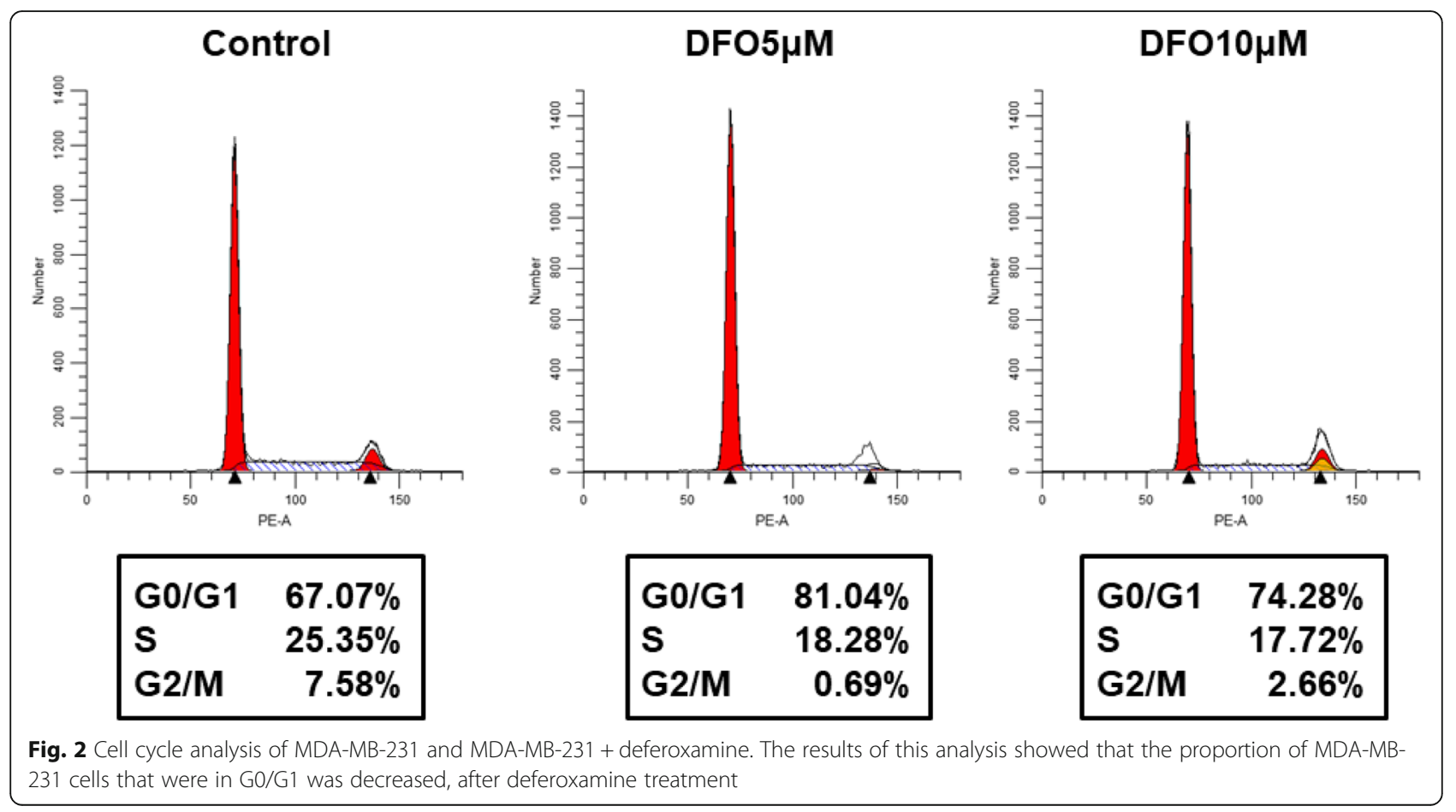




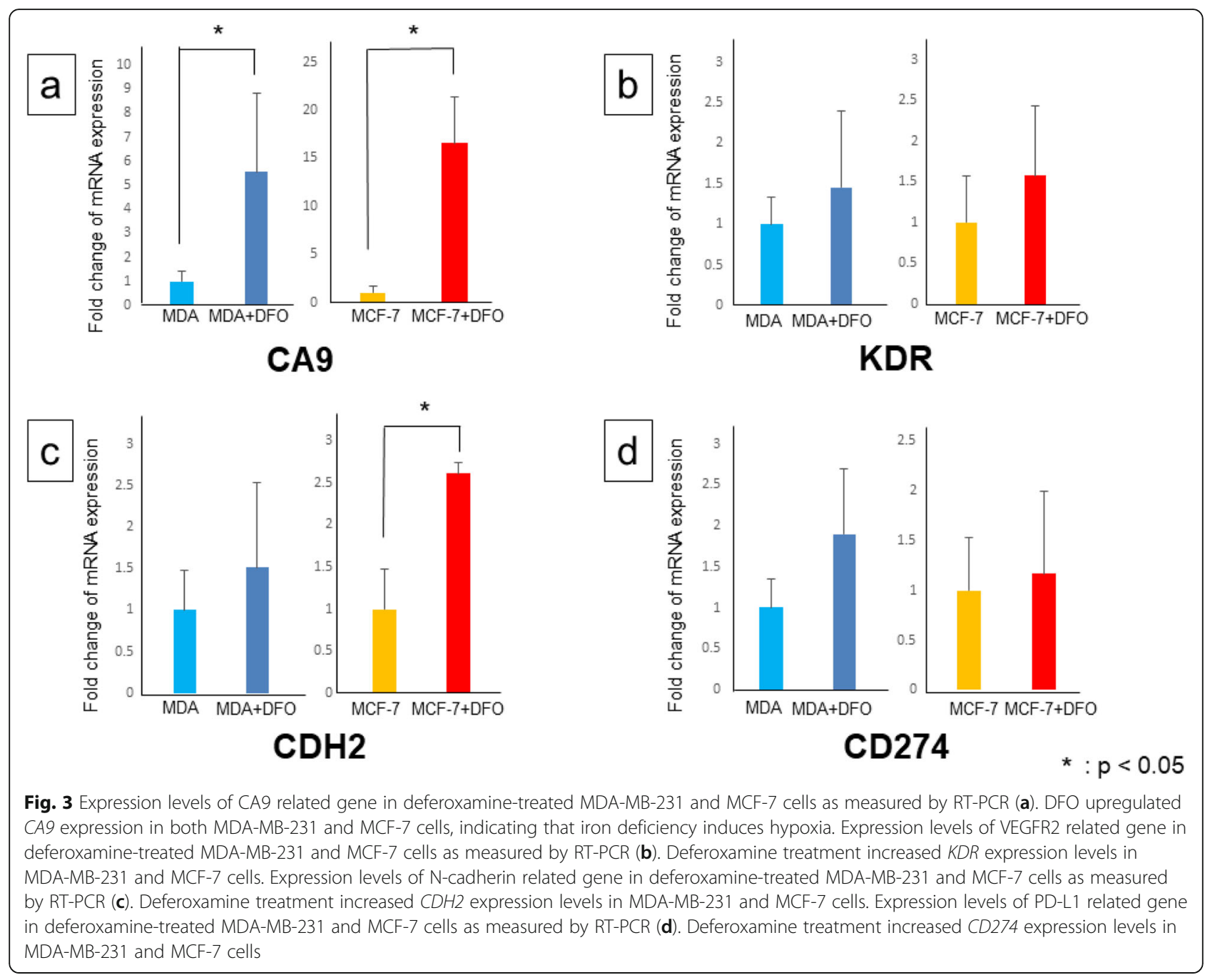

encodes N-cadherin, which is expressed by mesenchymal cells, and CD274 encodes programmed death-ligand 1 (PD-L1), which activates an immune checkpoint. $\mathrm{CDH} 2$ expression levels were higher in DFO-treated MDA-MB231 and MCF-7 cells than in untreated cells (Fig. 3c), as were $C D 274$ expression levels (Fig. 3d).

On the other hand, deferasirox also significantly upregulated CA9 expression in MDA-MB-231 and MCF-7 cells (Fig. 4a). However, administration of deferasirox did not significantly change the expression of $\mathrm{CDH} 2$ and $\mathrm{CD} 274$ in both MDA-MB-231 and MCF-7 cells (Fig. 4b, c).

\section{Effects of eribulin plus DFO on tumor growth in mice}

Our data suggest that DFO has both anti-oncogenic (inhibition of proliferation) and oncogenic (induction of hypoxia, EMT, and immune checkpoints) effects. Because we have shown that eribulin blocks these oncogenic events [13, 14], we asked whether DFO might more effectively suppress tumor growth in the presence of eribulin. Eribulin reduced CA9 expression in the presence of DFO, especially in BT-549 cells (Fig. 5a). In MDA-MB-231 cell lines, eribulin also significantly reduced expression of EMT related mRNA, $C D H 2$ and $Z E B 1$, in the presence of DFO (Fig. 5b,c). Regarding immune check points, eribulin did not significantly suppress CD274 expression in the presence of DFO (Fig. 5d). Importantly, DFO plus eribulin inhibited the growth of MDA-MB-231 xenografts in nude mice to a greater extent than did either agent alone (tumor volume: control $\left[270.0 \pm 35.7 \mathrm{~mm}^{2}\right]$, iron-deficient $\left[203.5 \pm 33.2 \mathrm{~mm}^{2}\right]$, eribulin $\left[141.9 \pm 15.1 \mathrm{~mm}^{2}\right]$, irondeficient + eribulin $\left.\left[96.3 \pm 13.8 \mathrm{~mm}^{2}\right]\right)(p=0.0181, p=$ $0.0067, p=0.0060$, respectively) (Fig. 6). HE staining showed that vessels were increased in MDA-MB-231 xenograft tissue treated with DFO. On the other hand, in the xenograft treated with DFO plus eribulin, vessels were not increased (Supplementary Fig. 1).

\section{Discussion}

In the present study, the iron chelator DFO suppressed breast cancer cell proliferation and tumor growth. In 


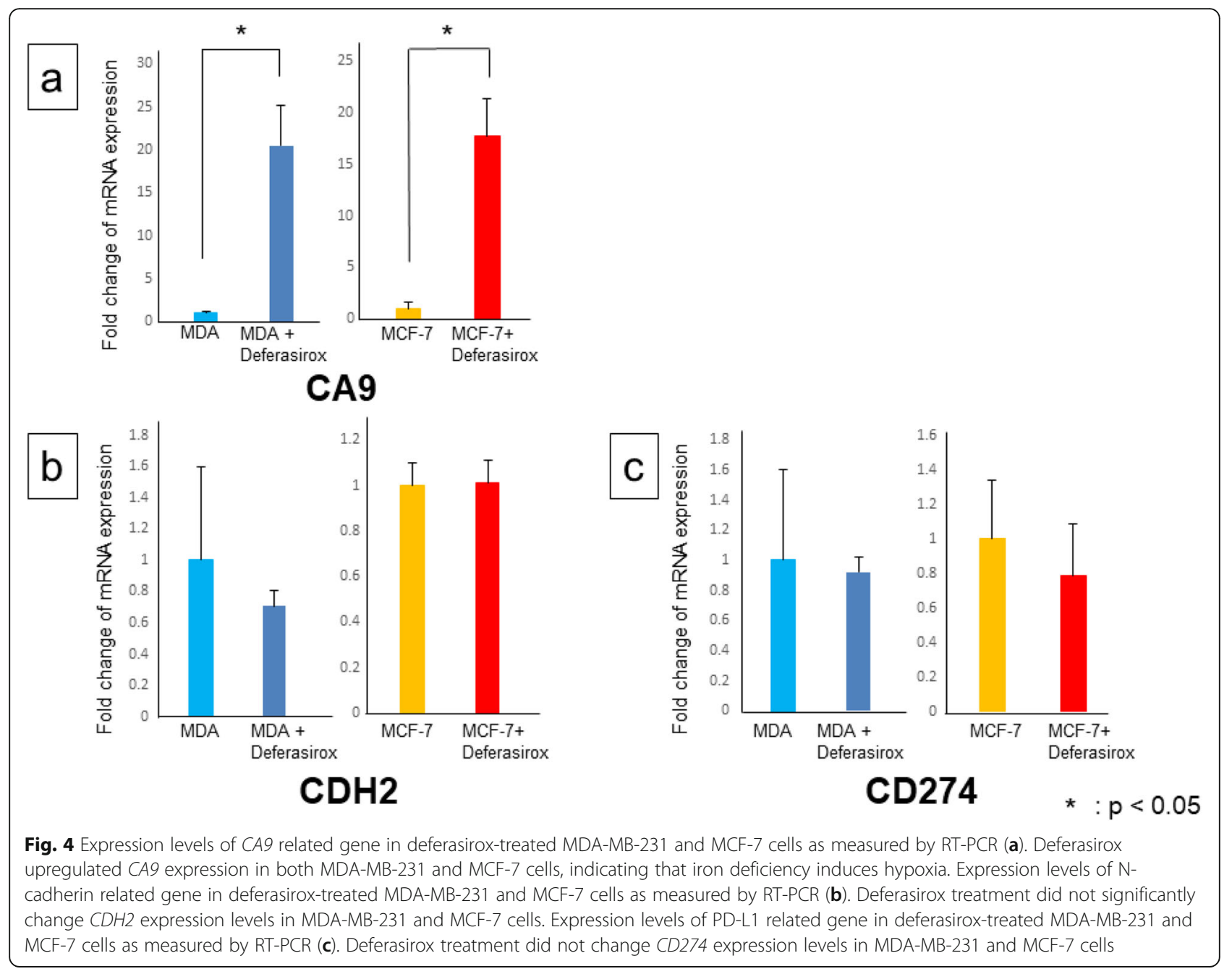

addition, iron-depleted condition may induce angiogenesis, hypoxia, EMT, and immune checkpoints. Regarding mechanism, we suggest that DFO promotes angiogenesis via hypoxia. To the best of our knowledge, our study is the first to examine the effects of iron depletion on the tumor immune microenvironment. Our model whereby DFO elicits its various effects is presented in Fig. 7.

As shown in a previous study, DFO induces hypoxia and the consequent expression of hypoxia-inducible factor-1 alpha (HIF-1 $\alpha)$ in breast cancer cells [19]. HIF-1 $\alpha$ initiates the transcription of genes encoding angiogenesispromoting proteins such as vascular endothelial growth factor [20]. It also increases TfR expression, stimulates iron uptake [2], and interacts with and stabilizes the tumor suppressor p53 [21, 22]. Once accumulated, p53 may induce G1/S arrest and apoptosis via its downstream effectors [23].

Although several factors promote the EMT via complex pathways, HIF- $1 \alpha$ is considered to be one of the most important [24]; it upregulates two EMT inducers, Snail and TWIST1 [25]. Hypoxia-induced HIF $\alpha$ has also been linked to immune checkpoint activation: in a previous study, it increased the expression of PD-L1 in myeloid-derived suppressor cells [26]. Furthermore, as shown by Noman et al., PD-L1 expression is upregulated in EMT-activated breast cancer cells, a process driven by various EMT transcription factors, including ZEB-1 and miR200 [27]. Based on these findings, we suggest that iron depletion induces the EMT and immune checkpoints via HIF-1 $\alpha$.

Because it elicits oncogenic events (hypoxia, EMT, and immune checkpoints), as well as anti-oncogenic events (G1/S arrest and apoptosis), iron depletion monotherapy is considered insufficient for the treatment of breast cancer. Hence, recent studies assessed the effectiveness of iron depletion plus chemotherapy. Hoke et al. found that the combination of DFO as an antioxidant and doxorubicin improved the outcomes of breast cancer patients, perhaps by reducing the toxicity of doxorubicin to cardiomyocytes and tumor growth [28]. Moreover, Ohara et al. reported that the combination of iron depletion and bevacizumab, an antiangiogenic drug, had dramatic synergistic antitumor effects [17]. 


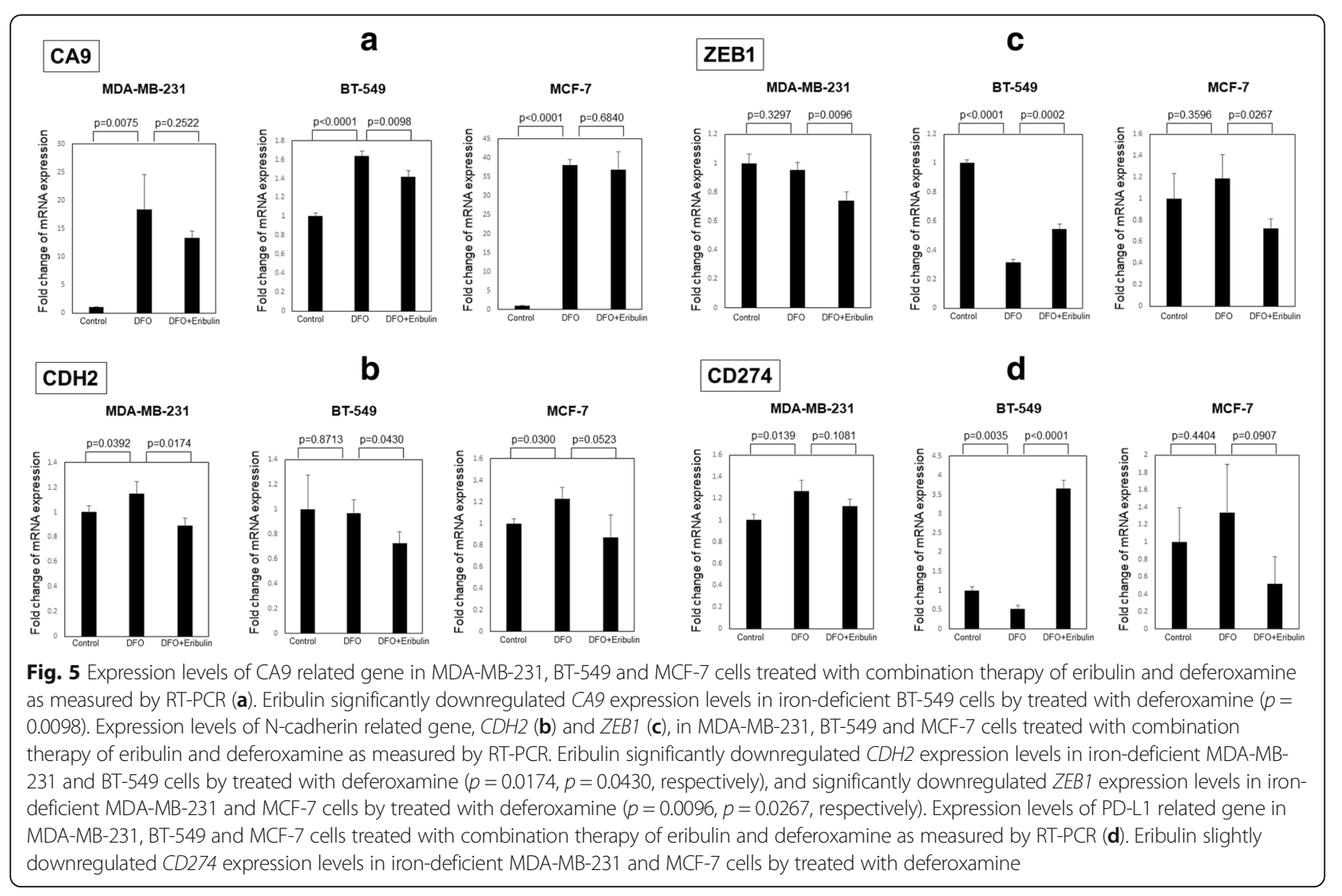

Eribulin is currently an approved treatment for patients with locally advanced or metastatic breast cancer. In a phase III trial (study 305/EMBRACE), eribulin significantly improved the overall survival of metastatic breast cancer patients who had previously undergone chemotherapy with anti-cancer agents such as anthracycline and taxane [29]. Since recent studies indicate that eribulin inhibits tumor hypoxia, EMT, and immune checkpoints [11-14], we hypothesized that iron depletion plus eribulin might be a useful therapy for breast cancer. No previous studies have investigated this combination therapy in breast cancer.

We found that the combination of DFO and eribulin had a significant antitumor effect in vivo compared with either inhibitor alone. Additionally, our qRT-PCR results suggest that eribulin more or less suppressed the induction of hypoxia, EMT, and immune checkpoints by DFO especially in MDA-MB-231 and MCF-7 cells. We previously used tumor-infiltrating lymphocytes to monitor the tumor immune microenvironment and propose that doing so is a valid means for evaluating the therapeutic effects of eribulin in TNBC cases [30]. This study showed that the effects of eribulin was associated with immune microenvironment. Our present study suggests that eribulin might act synergistically with DFO to suppress tumor growth in activated tumor immune microenvironments, such as those produced by DFO. Hence, eribulin plus iron depletion potentially represents a novel and practical treatment for breast cancer. However, eribulin incompletely suppressed the expression of the marker mRNAs for hypoxia, EMT, and immune checkpoints in DFO-treated cells (i.e., expression levels were higher in cells receiving eribulin plus DFO than in those receiving eribulin alone). Consequently, the effect of the combination on tumor suppression may be additive, not synergistic. In addition, even in the same TNBC cell lines, the change of $Z E B 1$ and $C D 274$ expression in BT-549 cells were different from MDA-MB-231. These results suggest that the mechanism of tumor immune microenvironment underlying iron deficiency may differ in various breast cancer cell lines. Moreover, according to deferasirox, another iron chelator, some previous studies revealed that deferasirox was noninferior or more effective than DFO regarding the iron removal $[31,32]$. In present study, though deferasirox showed inhibition of breast cancer proliferation and induction of hypoxia like DFO, it did not show the similar result with respect to EMT or immune check points. One of the possible reasons for these inconsistent results of in vitro experiments may be that DFO is an injection while deferasirox is an oral drug. Hence, further studies are necessary to decipher the complex 

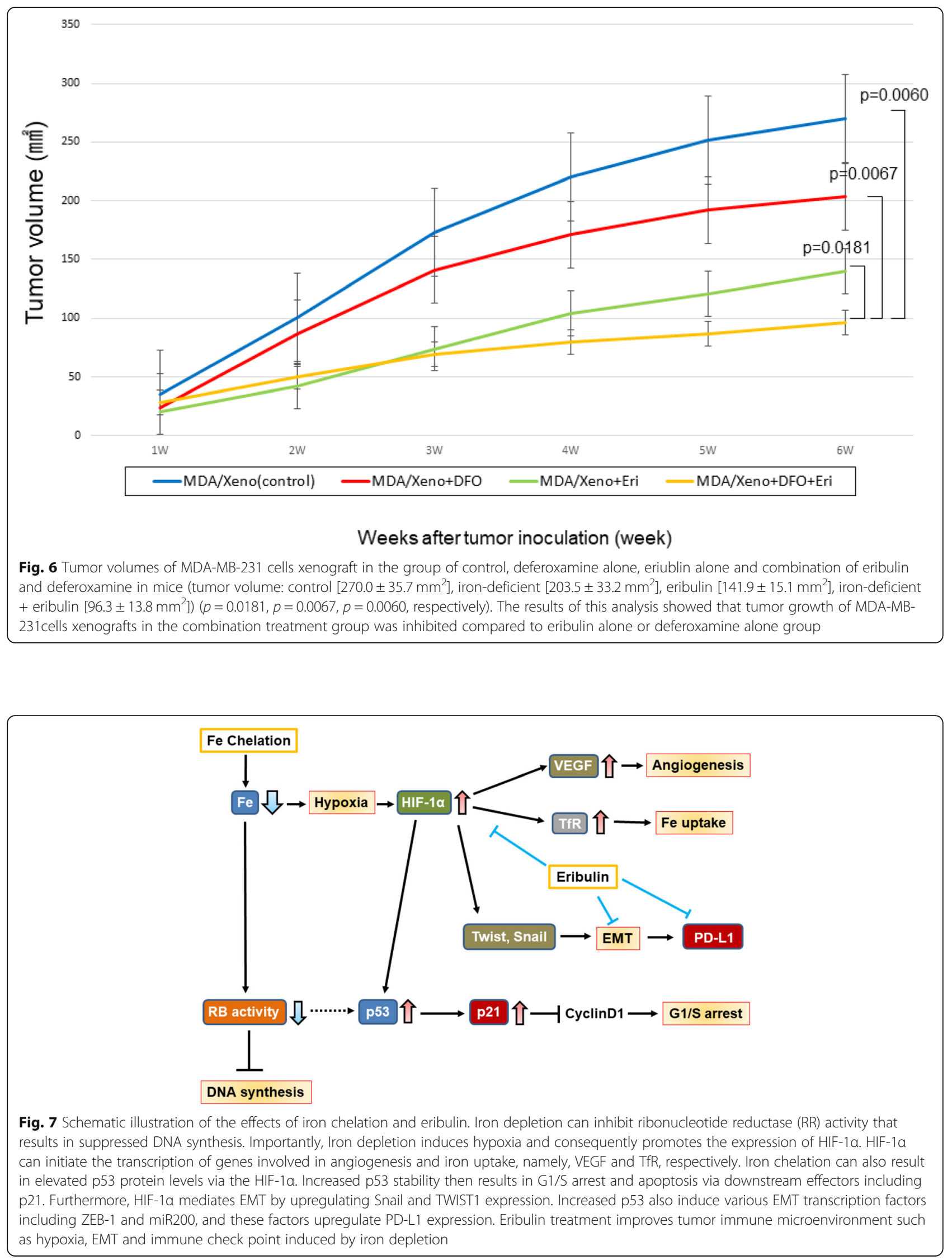
mechanisms underlying the effects of eribulin and DFO on tumor suppression and to design strategies for DFO and eribulin cotreatment of breast cancer patients in the clinical setting.

\section{Conclusions}

Iron depletion inhibits the proliferation and in vivo growth of breast cancer cells. Conversely, it induces hypoxia, EMT, and immune checkpoints in some breast cancer cell lines, thus creating an environment conducive for tumor growth. The combination of DFO and eribulin may be an effective treatment for breast cancer.

\section{Supplementary Information}

The online version contains supplementary material available at https://doi. org/10.1186/s12885-020-07673-9.

Additional file 1: Supplementary Fig. $1 \mathrm{HE}$ staining showed that vessels (arrow) were increased in the iron-deficient condition. However, vessels were not increased in the tumor treated with combination therapy, DFO plus eribulin.

\section{Abbreviations}

DFO: Deferoxamine; DMEM: Dulbecco's modified Eagle's medium

EMT: Epithelial-mesenchymal transition; FBS: Fetal bovine serum;

$\mathrm{NIH}$ : National Institute of Health; PD-L1: Programmed death-ligand 1; qRT-

PCR: Quantitative real-time-polymerase chain reaction; TfR1: Transferrin

receptor 1; TNBC: Triple-negative breast cancer

\section{Acknowledgements}

We thank Yayoi Matsukiyo and Tomomi Okawa (Department of Surgical Oncology, Osaka City University Graduate School of Medicine) for helpful advice regarding data management.

\section{Authors' contributions}

All authors were involved in the preparation of this manuscript. WG collected the data, and wrote the manuscript. SK, YA, KTakada, TM, KTakahashi and TT performed the operation and designed the study. WG, SK MS, RA and ST summarized the data and revised the manuscript. HF, KH and MO substantial contribution to the study design, performed the operation, and revised the manuscript. All authors read and approved the final manuscript.

\section{Funding}

This study was funded by grants from the Japan Society for the Promotion of Science (KAKENHI, Nos. 19 K18046, 26461957, and 17 K10559) to Shinichiro Kashiwagi.

\section{Availability of data and materials}

The datasets used and/or analyzed during the current study are available from the corresponding author on reasonable request.

\section{Ethics approval and consent to participate}

Mice experiments were conducted in accordance with $\mathrm{NIH}$ guidelines for the care and use of laboratory animals and approved by the Osaka City University Institutional Animal Care and Use Committee. This study did not involve human participants, human data or human tissue. Mammalian cell lines used in this study do not require ethics approval.

\section{Consent for publication}

Not applicable.

\section{Competing interests}

The authors declare that they have no competing interests.

\section{Author details}

'Department of Breast and Endocrine Surgery, Osaka City University Graduate School of Medicine, 1-4-3 Asahi-machi, Abeno-ku, Osaka 545-8585, Japan. ${ }^{2}$ Department of Pharmacology, Osaka City University Graduate School of Medicine, 1-4-3 Asahi-machi, Abeno-ku, Osaka 545-8585, Japan. ${ }^{3}$ Department of Scientific and Linguistic Fundamentals of Nursing, Osaka City University Graduate School of Nursing, 1-5-17 Asahi-machi, Abeno-ku, Osaka 545-0051, Japan. ${ }^{4}$ Department of Gastrointestinal Surgery, Osaka City University Graduate School of Medicine, 1-4-3 Asahi-machi, Abeno-ku, Osaka 545-8585, Japan. ${ }^{5}$ Department of Hepato-Biliary-Pancreatic Surgery, Osaka City University Graduate School of Medicine, 1-4-3 Asahi-machi, Abeno-ku, Osaka 545-8585, Japan.

Received: 25 February 2020 Accepted: 22 November 2020

Published online: 10 December 2020

\section{References}

1. Wang J, Pantopoulos K. Regulation of cellular iron metabolism. Biochem J. 2011:434(3):365-81.

2. Le NT, Richardson DR. The role of iron in cell cycle progression and the proliferation of neoplastic cells. Biochim Biophys Acta. 2002;1603(1):31-46.

3. Gao J, Richardson DR. The potential of iron chelators of the pyridoxal isonicotinoyl hydrazone class as effective antiproliferative agents, IV: the mechanisms involved in inhibiting cell-cycle progression. Blood. 2001;98(3): 842-50.

4. Nurtjahja-Tjendraputra E, Fu D, Phang JM, Richardson DR. Iron chelation regulates cyclin D1 expression via the proteasome: a link to iron deficiencymediated growth suppression. Blood. 2007;109(9):4045-54.

5. Hann HW, Stahlhut MW, Blumberg BS. Iron nutrition and tumor growth: decreased tumor growth in iron-deficient mice. Cancer Res. 1988;48(15): 4168-70.

6. Vaupel P, Mayer A, Briest S, Hockel M. Oxygenation gain factor: a novel parameter characterizing the association between hemoglobin level and the oxygenation status of breast cancers. Cancer Res. 2003;63(22):7634-7.

7. Kato J, Miyanishi K, Kobune M, Nakamura T, Takada K, Takimoto R, et al. Long-term phlebotomy with low-iron diet therapy lowers risk of development of hepatocellular carcinoma from chronic hepatitis C. J Gastroenterol. 2007;42(10):830-6.

8. Towle MJ, Salvato KA, Budrow J, Wels BF, Kuznetsov G, Aalfs KK, et al. In vitro and in vivo anticancer activities of synthetic macrocyclic ketone analogues of halichondrin B. Cancer Res. 2001;61(3):1013-21.

9. Kuznetsov G, Towle MJ, Cheng H, Kawamura T, TenDyke K, Liu D, et al. Induction of morphological and biochemical apoptosis following prolonged mitotic blockage by halichondrin B macrocyclic ketone analog E7389. Cancer Res. 2004;64(16):5760-6.

10. Jordan MA, Kamath K, Manna T, Okouneva T, Miller HP, Davis C, et al. The primary antimitotic mechanism of action of the synthetic halichondrin E7389 is suppression of microtubule growth. Mol Cancer Ther. 2005;4(7): 1086-95.

11. Funahashi $Y$, Okamoto $K$, Adachi $Y$, Semba $T$, Uesugi $M$, Ozawa $Y$, et al. Eribulin mesylate reduces tumor microenvironment abnormality by vascular remodeling in preclinical human breast cancer models. Cancer Sci. 2014; 105(10):1334-42.

12. Yoshida T, Ozawa Y, Kimura T, Sato Y, Kuznetsov G, Xu S, et al. Eribulin mesilate suppresses experimental metastasis of breast cancer cells by reversing phenotype from epithelial-mesenchymal transition (EMT) to mesenchymal-epithelial transition (MET) states. Br J Cancer. 2014;110(6): 1497-505.

13. Kashiwagi S, Asano Y, Goto W, Takada K, Takahashi K, Hatano T, et al. Mesenchymal-epithelial transition and tumor vascular remodeling in Eribulin chemotherapy for breast cancer. Anticancer Res. 2018;38(1):401-10.

14. Goto W, Kashiwagi S, Asano Y, Takada K, Morisaki T, Fujita H, et al. Eribulin promotes antitumor immune responses in patients with locally advanced or metastatic breast cancer. Anticancer Res. 2018;38(5):2929-38.

15. Goto W, Kashiwagi S, Asano Y, Takada K, Takahashi K, Fujita H, et al. The effects of Eribulin on breast cancer microenvironment identified using Eribulin-resistant breast cancer cell lines. Anticancer Res. 2019:39(8):4031-41.

16. Kasashima H, Yashiro M, Nakamae H, Masuda G, Kinoshita H, Morisaki T, et al. Bone marrow-derived stromal cells are associated with gastric cancer progression. Br J Cancer. 2015;113(3):443-52. 
17. Ohara T, Noma K, Urano S, Watanabe S, Nishitani S, Tomono Y, et al. A novel synergistic effect of iron depletion on antiangiogenic cancer therapy. Int J Cancer. 2013;132(11):2705-13.

18. Kitayama K, Yashiro M, Morisaki T, Miki Y, Okuno T, Kinoshita H, et al. Pyruvate kinase isozyme M2 and glutaminase might be promising molecular targets for the treatment of gastric cancer. Cancer Sci. 2017; 108(12):2462-9.

19. Liu Y, Cui Y, Shi M, Zhang Q, Wang Q, Chen X. Deferoxamine promotes MDA-MB-231 cell migration and invasion through increased ROSdependent HIF-1alpha accumulation. Cell Physiol Biochem. 2014;33(4): 1036-46.

20. Beerepoot LV, Shima DT, Kuroki M, Yeo KT, Voest EE. Up-regulation of vascular endothelial growth factor production by iron chelators. Cancer Res. 1996;56(16):3747-51.

21. Fukuchi K, Tomoyasu S, Watanabe H, Kaetsu S, Tsuruoka N, Gomi K. Iron deprivation results in an increase in p53 expression. Biol Chem Hoppe Seyler. 1995;376(10):627-30

22. An WG, Kanekal M, Simon MC, Maltepe E, Blagosklonny MV, Neckers LM. Stabilization of wild-type p53 by hypoxia-inducible factor 1alpha. Nature. 1998;392(6674):405-8.

23. Carmeliet $P$, Dor $Y$, Herbert JM, Fukumura D, Brusselmans $K$, Dewerchin $M$, et al. Role of HIF-1alpha in hypoxia-mediated apoptosis, cell proliferation and tumour angiogenesis. Nature. 1998;394(6692):485-90.

24. Jing Y, Han Z, Zhang S, Liu Y, Wei L. Epithelial-Mesenchymal transition in tumor microenvironment. Cell Biosci. 2011;1:29.

25. Cho KH, Yu SL, Cho DY, Park CG, Lee HY. Breast cancer metastasis suppressor 1 (BRMS1) attenuates TGF-beta1-induced breast cancer cell aggressiveness through downregulating HIF-1alpha expression. BMC Cancer. 2015;15:829

26. Noman MZ, Desantis G, Janji B, Hasmim M, Karray S, Dessen P, et al. PD-L1 is a novel direct target of HIF-1alpha, and its blockade under hypoxia enhanced MDSC-mediated T cell activation. J Exp Med. 2014;211(5):781-90.

27. Noman MZ, Janji B, Abdou A, Hasmim M, Terry S, Tan TZ, et al. The immune checkpoint ligand PD-L1 is upregulated in EMT-activated human breast cancer cells by a mechanism involving ZEB-1 and miR-200. Oncoimmunology. 2017;6(1):e1263412.

28. Hoke EM, Maylock CA, Shacter E. Desferal inhibits breast tumor growth and does not interfere with the tumoricidal activity of doxorubicin. Free Radic Biol Med. 2005;39(3):403-11.

29. Cortes J, O'Shaughnessy J, Loesch D, Blum JL, Vahdat LT, Petrakova K, et al. Eribulin monotherapy versus treatment of physician's choice in patients with metastatic breast cancer (EMBRACE): a phase 3 open-label randomised study. Lancet. 2011;377(9769):914-23.

30. Kashiwagi S, Asano Y, Goto W, Takada K, Takahashi K, Noda S, et al. Use of tumor-infiltrating lymphocytes (TILS) to predict the treatment response to eribulin chemotherapy in breast cancer. PLoS One. 2017;12(2):e0170634

31. Pennell DJ, Porter JB, Piga A, Lai Y, El-Beshlawy A, Belhoul KM, et al. A 1 -year randomized controlled trial of deferasirox vs deferoxamine for myocardial iron removal in $\beta$-thalassemia major (CORDELIA). Blood. 2014;123(10):1447-54

32. Al-Kuraishy HM, Al-Gareeb A, et al. Comparison of deferasirox and deferoxamine effects on iron overload and immunological changes in patients with blood transfusion-dependent $\beta$-thalassemia. Asian J Transfus Sci. 2017;11(1):13-7.

\section{Publisher's Note}

Springer Nature remains neutral with regard to jurisdictional claims in published maps and institutional affiliations.

Ready to submit your research? Choose BMC and benefit from:

- fast, convenient online submission

- thorough peer review by experienced researchers in your field

- rapid publication on acceptance

- support for research data, including large and complex data types

- gold Open Access which fosters wider collaboration and increased citations

- maximum visibility for your research: over $100 \mathrm{M}$ website views per year

At BMC, research is always in progress.

Learn more biomedcentral.com/submissions 